\title{
Revisitando el pensamiento de Hannah Arendt y Norbert Lechner: hacia un Trabajo Social crítico ${ }^{12}$
}

\author{
Claudia Garrido Carrasco ${ }^{3}$
}

\section{RESUMEN}

Las contribuciones teóricas de Hannah Arendt y de Norbert Lechner coinciden en el diagnóstico y descripción de un anquilosamiento de las instituciones políticas, de una crisis de representación y legitimidad, y de una burocratización de los partidos políticos disociados de la experiencia de la vida cotidiana de sus electores. Centrándonos en una doble valoración de dichas contribuciones, vale decir, asumiendo por un lado sus aspectos críticos de la política institucional y el sistema democrático liberal, pero también aprehendiendo las intuiciones que esas críticas suponen, en el sentido de apostar por una política que recupere las nociones de libertad e igualdad, nos proponemos elaborar una integración conceptual reflexiva desde la disciplina de Trabajo Social, de dimensiones no incorporadas en la política -institucional- que nos permita comprender los fenómenos actuales de politización colectiva -no institucional-.

Palabras clave: Teoría crítica, vida cotidiana, politización, Trabajo Social.

\section{Revisitando o pensamento de Hannah Arendt e Norbert Lechner: Para um Trabalho Social crítico}

\section{RESUMO}

As contribuições teóricas de Hannah Arendt e de Norbert Lechner, coincidem no diagnóstico e descrição de uma atrofia das instituições políticas, de uma crise de representação e legitimidade, e de uma burocratização dos partidos políticos dissociados da experiência da vida cotidiana dos seus eleitores. Pondo o centro em uma dupla valoração de ditas contribuições, quer dizer; assumindo por um lado seus aspectos críticos da política institucional e o sistema democrático liberal, mas também apreendendo as intuições que essas críticas supõem no sentido de apostar por una política que recupere as noções de liberdade e igualdade, é que nos propomos elaborar una integração

1 Artículo recibido el 28/09/2017. Artículo aprobado el 3/03/2018

2 Algunas de las ideas aquí expresadas forman parte del trabajo doctoral de la autora.

3 Chilena. Trabajadora Social, Investigadora del grupo de trabajo Reinvenciones de lo Común, CLACSO. E-mail: clagarri@ucm.es 
conceptual reflexiva desde a disciplina de Trabalho Social, de dimensões não incorporadas na política -institucional- que nos permita compreender os fenômenos atuais de politização coletiva -não institucional-.

Palavras-chave: Teoria crítica, vida cotidiana, politização, Trabalho Social.

\title{
Reviewing the thinking of Hannah Arendt and Norbert Lechner: Towards a critical Social Wor
}

\author{
ABSTRACT
}

\begin{abstract}
Both Hannah Arendt and Norbert Lechner's theoretical contributions coincide in their diagnosis and description of the stagnation of political institutions; of a crisis of representation and legitimacy; of the bureaucratization of political parties completely detached from the everyday-life experience of their voters. This study focuses on a double appraisal of these contributions, - that is, accepting both authors' criticisms of institutional politics and the liberal democratic system while also apprehending the intuitions implied by these criticisms (insofar as they propose a form of politics that reclaims the notions of freedom and equality.) Through this appraisal we attempt to develop a reflexive conceptual integration, from the discipline of Social Work, on dimensions which lie outside of - institutional - politics, in an effort to understand contemporary phenomena of collective non-institutional politicization.
\end{abstract}

Keywords: Critical theory, everyday-life, politization, Social Work.

\section{Introducción}

A la luz de los resultados del informe del Programa de las Naciones Unidas para el Desarrollo, PNUD, del año 2015, que analiza el proceso de politización que se vive en Chile, retomamos una premisa central del desarrollo humano, aquella que plantea la transformación de las personas a nivel individual y colectivo en sujetos capaces de ser constructores de su propia vida -telos de la disciplina de Trabajo Social-. Esta orientación presupone un desafío para la política que, en su vertiente más procedimental, no incorpora los procesos de politización y conflictividad de nuestra sociedad actual.

Ese mismo informe plantea un escenario de cuestionamiento de los parámetros tradicionales con que en Chile se evaluaban las instituciones. Hoy la tensión se expresa entre la eficiencia y la legi- 
timidad en la toma de decisiones, como a su vez entre los criterios jurídicos y los ético-morales. Dicha coyuntura, según lo expresa el Informe PNUD (2015), no se debe tanto a un bajo rendimiento de las instituciones, sino sobre todo a cómo las formas institucionales se adecuan (o no) a un nuevo escenario de resignificación del tipo de relaciones que los/as ciudadanos/as anhelan construir.

Desde las consideraciones antes expresadas, un Trabajo Social crítico que se asuma como disciplina tensionada en el binomio dominación/emancipación, recoge la pregunta que los procesos de politización nos plantean. ¿El criterio de legitimidad social es jurídico-institucional o es ético-moral? A su vez, el telos de transformación que actúa de horizonte de Trabajo Social, ¿considera que las vías para dicha transformación son institucionales o no institucionales?

En razón de lo anterior, reflexionamos en torno a los conceptos de "acción" y "subjetividad política" desarrollados por Hannah Arendt y Norbert Lechner, respectivamente, apostando por la profundización de una teoría crítica de la vida cotidiana, a la que consideramos un espacio factual de ocurrencia de interpelaciones: el lugar donde el poder se transforma en orden. Desde nuestra perspectiva, esta es una dimensión política insoslayable, que refiere al ámbito de relaciones complejas en que se autoreproduce toda la vida social, en tanto espacio microfísico de atribución de sentidos a las prácticas políticas colectivas a través de las cuales las personas se reconocen entre sí. Como microrealidad, permite reconstruir los ejes en que se organizan y/o clasifican las representaciones simbólicas que orientan la vida de una determinada sociedad; entendiendo a la vida cotidiana solo como uno de los ámbitos en el que los sujetos politizan el debate acerca de lo público y que en ningún caso acota la diversidad de escenarios en que puede ocurrir la politización.

\section{Revitalizar la acción y la subjetividad política}

Tanto Hannah Arendt como Norbert Lechner mantuvieron en sus desarrollos teóricos una constante atención a los fenómenos polí- 
ticos de los que fueron testigos. Ambos comparten un interés en revitalizar o dignificar la política, dándole un nuevo sentido reflexivo en el contexto de su denigración o intentos de abolición. En coherencia con ello, nuestro interés, desde la teoría política y la disciplina de Trabajo Social, es intentar no solo comprender estos fenómenos, sino también hallar una esperanza de transformación, indagando en las posibilidades que permitan continuar en la lucha por el encuentro de mujeres y hombres en el espacio público, los que, vinculados a través de las palabras y los actos y trascendiendo su individualidad, se pongan al servicio de la construcción de lo común, de lo solidario y de lo que dignifica la existencia humana. Lo anterior, con el fin de recuperar aquello que en la antigüedad clásica remitía a una de las más excelsas de las virtudes: la participación libre en la vida pública, en definitiva la política.

\section{Sobre la acción política}

En la elaboración de su concepto de "acción política", Arendt nos retrotrae hasta la isonomía griega, en la que no había mando ni sujeción, no existiendo la noción de autoridad. Este es el aspecto de una libertad negativa, que requiere como condición no dominar ni ser dominado, y positiva, en tanto la libertad se realizaba en la polis porque todos eran iguales, políticamente hablando, es decir: liberados de las necesidades más apremiantes para la participación y discusión de aspectos comunes que trascendieran sus propios intereses. La igualdad política es artificial, en el sentido de que es creada por la propia relación entre las personas reunidas en torno a lo común y a la participación en la polis. Sobre esta base, Arendt formula su noción de especificidad de la política; interpretamos que, como forma de poner el acento en la experiencia de libertad, distinta de la liberación de necesidades. Desde esta constatación, la autora expone en Sobre la Revolución (1967) un problema en la concepción de los derechos del Estado moderno, y es el que dice relación con la garantía constitucional de los derechos de ciudadanía (libertades de circulación, de coerción, de movimiento, derecho de reunión o de petición), los cuales son requisitos pa- 
ra la libertad pública, pero no su sustancia. Arendt es enfática en subrayar que existe una distinción entre las leyes necesarias para el ejercicio de esos derechos y la constitución de una verdadera libertad política. Las primeras, nunca han sido el contenido real de la libertad, el que solo se corresponde con la participación en los asuntos públicos y/o la admisión en la esfera pública.

Lo que aprehendemos de la intelección arendtiana es que la participación en los asuntos comunes representa en el acto mismo de reunión un ejercicio de libertad, no considerada ésta (tampoco la igualdad) como un fin a alcanzar, sino como el sentido mismo de la existencia: lo político es la participación. De este hecho extraemos dos ideas; la primera, que el concepto de libertad política se diferencia de su par moderno, en tanto no se transforma en medio para asegurar la existencia humana, resguardar la propiedad privada o asegurar el progreso; la segunda es que el objetivo de la política es mantener y/o crear espacios de aparición pública. Arendt reconoce que incluso en un momento de revolución puede, la libertad, transformarse en el objetivo directo de la acción política momentos que la autora denomina "natalidad" o "milagro" (debido a su imposibilidad de predicción)-; no obstante, la mantención de una organización política es lo que otorga sentido a la política misma. De este modo, asumimos que la praxis cotidiana actualiza relaciones de poder y las instituye, apropiándonos así de la noción arendtiana de espontaneidad e impredictibilidad de la acción política. Vida cotidiana que interpretamos como latencia o predisposición a lo común, como rizoma, en sentido deleuziano (1988); es decir, como conexiones múltiples y heterogéneas de relaciones, y no como un entramado de roles formalizados y/o preconstituidos.

La acción política hace posible la existencia de la memoria y, con ello, la conservación del "mundo"; siendo su criterio de grandeza la capacidad de actuación colectiva para transformarlo. Es el poder colectivo lo que preserva la esfera pública mediante la acción y el discurso. Su significado entonces reside en la realización misma, a la que con Tassin (2010) denominamos "manifestación”, ya que en el fenómeno político -que es contingencia en tanto ocurre 
y discurre- se funda y hace visibles a los actores y sus actuares colectivos, porque la acción exhibe insurgencia y en su aspecto de impredictibilidad rompe con el repertorio esperado: estrategias, medios, instrumentalidad, asignación de roles y preocupación por los resultados o productos de la acción. Y, nuevamente con Tassin (2010), nos permite pensar una acción política distinta a la definida por los encuadres de gubernamentalidad, procesos de participación, mecanismos de integración u otras conceptualizaciones propias de la política institucional moderna.

Esta perspectiva arendtiana sobre la acción como manifestación, sitúa lo político más allá del acierto y el fracaso, a la manera en que Nietzsche situaba la moral más allá del bien y el mal. Porque evidencia una paradoja: al igual que las revoluciones modernas, la acción política democrática, entendida como manifestación, falla casi siempre: es vano esperar de ella una eficacia proporcional al esfuerzo que ella representa. Pero ahí está la paradoja: es en esta derrota que anida su victoria, puesto que se aleja lo más posible de toda ingeniería social. La política es la producción de lo visible y su constante partición y repartición (partage), y no la disposición siempre contra-efectiva del poder, o la gestión siempre decepcionante de lo social. (Tassin, 2010: s/n)

La acción política arendtiana, al ser pensada como acontecimiento o manifestación, actualiza la intelección aristotélica de la energeia (realidad), que no tiene otro fin aparte de sí misma (Arendt, 1958), lo cual significa que no hay nada más elevado que la realidad misma, retrotrayéndonos también a la noción de eterno retorno nietzscheano para subrayar la eternidad del instante mismo:

¡Mira este pórtico, enano! [...]. Tiene dos rostros. Aquí se reúnen dos caminos; nadie los ha recorrido hasta ahora totalmente. Esta larga calle que desciende, esta calle se prolonga durante una eternidad, y esta larga calle que sube es...otra eternidad. Estos caminos se contradicen, chocan el uno con el otro, y es aquí, en este pórtico, donde se reúnen. El nombre del pór- 
tico aparece grabado en un frontis: se llama "instante". Pero si alguien siguiera uno de estos dos caminos, yendo cada vez más lejos, ¿crees tú, enano, que estos caminos entrarían en contradicción? (Nietzsche, 1973: 150)

Beiner (2003) se pregunta cómo es posible que un "instante" pueda sostener todo el sentido de la existencia, argumentando que Arendt halla esta respuesta inicialmente en el concepto de acción política (natalidad) y, en obras posteriores, en el juicio histórico. Ya que la acción, por sí sola, no podía ser el soporte contra la fugacidad del tiempo, la autora habría buscado una forma de inmortalizarlo: rescatar la gloria del acontecimiento, de la revolución; en definitiva, de la acción política, por el solo hecho de representar la capacidad humana para las grandes gestas en una dignidad particular que, como expresa Beiner, ninguna generalidad o universalidad puede arrebatarle. Es en los actuales escenarios de denigración de lo político donde adquiere mayor fuerza la potencialidad de la acción política: "un modo de recuperar nuestra ciudadanía, en ausencia de un auténtico ámbito público" (Ibid, p. 265).

Este es el auténtico contenido de la doctrina del Eterno Retorno, que la eternidad está en el Instante, que, a los ojos del espectador, el Instante no es el fugitivo ahora, sino la colisión entre pasado y futuro. (Heidegger, citado por Arendt, 1984, pp. 234-235).

En estas argumentaciones reside la fundamentación de todo el arte de lo político: dar a luz lo extraordinario por medio de la acción; un fin en sí mismo.

\section{Sobre la "subjetividad política"}

Entendemos este concepto, a partir de los trabajos de Lechner, como una dimensión de la vida política que incorpora las luchas por la subjetivación de los sujetos y la construcción de cartografías emocionales y cognitivas que dan cuenta del mundo en que vivimos. Aquí la noción arendtiana de "mundanidad", aparece como significante en la articulación de los imaginarios colectivos. 
La "subjetividad política", representa, por un lado, un proyecto de secularización de la política, en el sentido de que la politización en la vida cotidiana, al actuar como principio de organización social, asume una función de "integración" de la pluralidad de proyectos que disputan su legitimidad en el espacio público. Y, por otro, indica una necesidad de elaborar demarcaciones -delimitación del orden social- que permitan una convivencia política deliberativa, es decir, que hagan plausible las relaciones en armonía pero, a su vez, incorporen la conflictividad social (las luchas por la autodeterminación).

La fundamentación de dicho orden requiere imbricar dos aspectos de la democracia: 1) la relación entre un orden conflictivo y 2) la creación de un orden colectivo. En este sentido, asumimos la noción de democracia no como una forma de gobierno, sino como Estado constituyente que, críticas aparte -en el sentido en que Negri (2016), la plantea como concepto discutible y necesariamente asociado a la vía institucional-, puede pensarse como articulador de la praxis y como noción de ruptura que anida una multiplicidad de contrapoderes. Esto nos sitúa en la perspectiva revolucionaria de Arendt: pensar la irrupción de la acción al mismo tiempo que su elemento de conservación en la memoria histórica gracias a la narración de los hechos; acciones que, a su vez, se inscriben en una trama de acciones precedentes pero en la que se inserta siempre una novedosa oportunidad de acto fundante, ubicándonos en una reflexión de la democracia como acto y proceso.

Lechner asume que la consistencia de las instituciones democráticas depende de su capacidad de continuidad temporal, es decir, la democracia adquiere mayor condición de posibilidad si logra estructurar un horizonte compartido. Lo que requiere tanto del análisis de nuevos asuntos en la vida cotidiana que devienen públicos, como de una recuperación de la convivencia social en tanto orden construido. Con Lechner, entendemos que la incorporación de las decisiones colectivas como asuntos públicos exige un ejercicio de democracia inclusiva que cuestiona el diseño de la democracia liberal representativa. En esta tensión donde cabe la consideración 
de procesos de politización que expresan deseos subyacentes en la vida cotidiana, capaces de orientar el sentido de las transformaciones sociopolíticas y culturales y que son, por antonomasia, el escenario/posibilidad para el despliegue de un Trabajo Social crítico.

Poner en cuestión al modelo de democracia representativa conlleva una propuesta de democracia desde la reciprocidad. Esto quiere decir, con Lechner, abogar por el desarrollo de una teoría de la democracia basada en los fundamentos de una subjetividad política, en la cual cabe el estudio de la constelación de invocaciones y articulaciones de significados a través de las cuales se constituyen los sujetos, y cuyo centro de estudio sean aquellas prácticas cotidianas en la que se recrean sentidos y expresan deseos, configurándose además disputas en torno a éstas. Con ello, se revitalizaría un tema crítico de la teoría política, y es el que se relaciona con el estudio del mecanismo en que se establecen las luchas de poder en la dimensión de la vida cotidiana, en tanto éstas se hacen parte del ámbito público. En definitiva, se plantea como desafío la contribución a un análisis de los "nuevos asuntos políticos", abriendo paso a la elaboración de herramientas para cartografiar diversos modos de organización en la vida cotidiana. De lo anterior se desprende la concepción de Lechner como "sujetos-en-devenir", con la que piensa en la autodeterminación de los sujetos a través de los procesos de subjetivación; pudiendo ser la subjetividad política: un principio constitutivo de un proyecto de emancipación social.

\section{Articulación de una propuesta de politización en la vida cotidiana}

La política moderna asume una lógica de eficiencia, toda vez que los actores de la esfera pública calculan los costos de sus decisiones bajo criterios de objetividad, siendo la subjetividad desplazada hacia lo privado, ya que los juicios de valor serían una cuestión de conciencia individual. Desde ese punto de vista, la identificación del ciudadano/a corresponde a la de un individuo consumidor y votante, siendo aplicable aquella consiga que nos recuerda Arendt en 
"Sobre la Revolución" (1967): todo el poder del pueblo únicamente el día de las elecciones. Y, no obstante se reconozca que en la vida práctica-cotidiana se presenten dificultades, éstas no son incorporadas como preocupación política, pasando por alto su carácter colectivo y creativo de vínculos sociales, como también su estatus de praxis en que se manifiestan fenómenos emocionales y cognitivos que asignan significados a la memoria colectiva y que, en tanto tal, serán transmitidos como aprendizajes y saberes de dicho hacer político.

Hannah Arendt concebía la esfera pública como un espacio fundado sobre la acción comunicativa y el poder colectivo que surge de esa acción, alejado de la violencia. Ese espacio político estará caracterizado por la pluralidad, el disenso, la ciudadanía, la solidaridad, la acción y la República como sistema de gobierno (Sánchez, 2003). Una revolución puede iniciarse violentamente pero, para que ésta triunfe, deberá dar paso a la negociación, el diálogo y la mediación, elementos del ámbito y ejercicio político.

La revolución, cuya definición arendtiana ampliamos hacia los procesos de construcción del espacio público mediante la praxis colectiva, de la acción misma de los ciudadanos que se interesan por los asuntos políticos y como autoorganización de la política, puede ocurrir en paralelo a la inmovilidad del aparato estatal. De hecho, lo político surge más allá de las responsabilidades institucionales y esto es muchas veces ignorado por quienes equiparan la política con el Estado, con el sistema político o con las responsabilidades formales (Beck, 1998). A esto se refiere Beck cuando señala el renacimiento de una subjetividad política, en tanto las iniciativas ciudadanas muchas veces logran un poder temático.

Ya la noción arendtiana de inter est o en medio de subjetivo, que vincula a las personas a través de los hechos y palabras en la acción política, al igual que su crítica al materialismo aristotélico, nos revelaba el carácter intangible de la acción política, el que aquí hemos incorporado en la categoría de "subjetividad política"; fenómeno que enmarca los procesos de politización en la vida cotidiana. El objetivo de la "politización" es la exposición de temas 
puestos en marcha por la propia acción y expresión de la subjetividad: que es política en sí misma, ya que retomaría el antiguo sentido griego al no perseguir un fin instrumental. Esto se diferencia de la política de los partidos, orientada por fines y estrategias y estructurada en torno a una determinada forma de hacer las cosas: burocratizando, persiguiendo objetivos y estableciendo jerarquías para su cumplimiento.

A partir del debate teórico en torno a la crisis de la política institucional, es posible articular una noción de politización de la vida cotidiana como recuperación del espacio público y, por consiguiente, proponer una praxis de Trabajo Social que, más allá de marcos de institucionalidad formal, recree una acción crítica.

Solo como ejemplo, podemos observar una de las cuestiones que evidencia la crisis democrática actual, constatable por un lado en los actos de violencia e incriminación delictiva en contra de quienes participan de acciones de protesta en el espacio público y, por otro, en la redacción de leyes que la obstaculizan -véase el estudio Leyes mordaza y criminalización de la protesta en el estado español (Bondia, Daza, et al, 2015) y el Informe Radde Criminalización de la movilización estudiantil en Chile en el año 2011, proyectos legales surgidos con posterioridad a los estallidos del movimiento de los indignados del 15-M en España y del movimiento estudiantil chileno-. Ya Lechner, en su ensayo Estado y política en América Latina (1981), identificaba los procesos de criminalización como una serie de fases puestas en ejecución, siendo la primera la socialización de un discurso orientado a la integración del "desvío", mediante un énfasis de la identidad de consumidor, seguida por el cuestionamiento $y$, agregamos, desmantelamiento del Estado de Bienestar (toda una serie de recortes en las áreas de mayor impacto social: educativa, cultural y de sanidad pública), hasta (cuando lo anterior no arroja el resultado de "integración") la criminalización directa de las demandas populares, siempre tratadas como un problema individual.

La criminalización de la protesta nos sitúa, a su vez, en un campo de disputa de hegemonías en que se dirime qué es lo que enten- 
deremos por político y por no político, escenario en que Lechner articuló su noción de "subjetividad política", criticando la lógica jurídico-individualista.

La tesis de Lechner puede ser interpretada como una lectura del intento autoritario (institucional) de resignificar el ámbito público-político, evidenciando aquello que Arendt manifestaba en Sobre la Revolución (1967) con un determinado convencimiento: el pueblo tiene la reserva de la rebelión, cuestión que con Lechner podemos expresar como una relación de fuerzas en las que, a mayor delimitación autoritaria contra las demandas sociopolíticas, mayor el surgimiento de nuevas formas de actuar que conducen a una nueva concepción política. El autor describe dos momentos de la misma operación: despolitización -en el que se prohíbe hacer política (el totalitarismo descrito por Arendt y la dictadura reseñada por Lechner)- y re-politización, en que se abren nuevas perspectivas políticas a través de acciones que, parafraseando a los autores, resisten al poder (institucional y/o criminalizante), abriendo las fisuras por donde emerge lo creativo-político conscientemente, en contra de la instrumentalización y elitización que de la política se hace por parte de los poderes institucionales.

El ámbito de la vida cotidiana permite la reivindicación de una responsabilidad por la construcción de lo común, pese a que su subjetividad pueda ser neutralizada por la formalidad institucional, como nos advierte Lechner (1986), pero en ningún caso eliminada del campo político; conclusión en la que coincide con Arendt (excepción hecha con el totalitarismo) quien, como ya se ha consignado, plantea como recurso la reserva de la revolución que siempre reside en el pueblo; poder que con Foucault (1992), entendemos, no se produce por la mera expresión de las identidades colectivas (o individuales), sino por el hecho de ejercerlo, de producir poderes múltiples y efectos de poder.

Esto es precisamente lo que hacen los revolucionarios. ¡Los revolucionarios no hacen las revoluciones! Los revolucionarios son los que saben cuándo está el poder abandonado en la calle 
y cuándo pueden recogerlo. La rebelión armada en sí misma jamás ha conducido a la revolución. (Arendt, 1973, pp. 207-208)

De acuerdo con lo antes expuesto, entendemos que los intereses colectivos intangibles se orientan a la transformación de la subjetividad de la vida cotidiana, ámbito sobre el que pueden operar formas de control institucional (mecanismos de privatización o retracción de la vida social) con el fin de despolitizar la esfera de lo público, desocializando a la política.

Lo antes reseñado permite hacer explícita la necesidad de analizar las definiciones de "legitimidad" en los escenarios políticos actuales y en consideración de los momentos institucionales, pero con énfasis en los procesos de politización de la vida cotidiana. Si "legitimidad" se entiende como el consentimiento voluntario de un pueblo concedido a un determinado gobierno para tomar decisiones en representación de su voluntad, nos preguntamos:

¿Qué procesos operan en la vida cotidiana cuando esa legitimidad es retirada en virtud de hechos que van en contra de los intereses del pueblo? ¿Qué posibilidades de representación tienen los intereses diversos, complejos y cambiantes de la vida cotidiana? ¿Quiénes pueden construir y aunar subjetividades? ¿En qué ámbito tiene factibilidad la articulación de una intersubjetividad como proyecto sociopolítico alternativo? ¿Cuáles son los referentes mediante los cuales se mediatizan las frustraciones, posibilidades y deseos políticos surgidos en el ámbito de la vinculación colectiva de la vida cotidiana? En definitiva: ¿dónde halla la disciplina de Trabajo Social un telos que devuelva a lo colectivo su capacidad de acción política, contrarrestando así los procesos de individualización y consumo?

Ahora bien, la disciplina de Trabajo Social no es ajena a los mecanismos procedimentales que estructuran la política moderna y que específicamente le demandan productividad en su quehacer. Piénsese por ejemplo en el requisito cuantitativo de beneficiarios para operacionalizar la política pública. Este énfasis en la administración burocrática de las necesidades es el que nos imposibili- 
ta una acción profesional ligada a cuestiones más sustantivas, que permita una producción de conocimiento crítica. Lo antes descrito nos aleja del alma disciplinar reflexiva (Yañez, 2007).

Por lo tanto, una posibilidad de asumir este desafío disciplinar crítico en las condiciones sociopolíticas actuales es observar cuáles son nuestras formas de producción de conocimiento. Si la ciencia es un modo cultural de ver la realidad (Panikkar, 2009), entonces asumimos que nuestras epistemologías no pueden estar escindidas de los problemas sociales y de la construcción de democracias radicales. Quizá la revitalización de los conceptos de "concientización”, "organización” y "movilización” nos hagan sentido si pensamos en un Trabajo Social inmerso en los procesos de politización.

Lo antecedente insta a preguntarnos no solo desde qué marcos de comprensión nos acercamos a los fenómenos político-sociales, sino también ¿quién está definiendo lo que necesitamos saber? ¿Quién y cómo se priorizan las áreas de financiamento? Ello nos insta a desbordar la instrumentalidad de una política social neoliberal y productivista, para pensar la creación de conocimiento fuera de ella. Esto significa asumir una política de la contingencia, en el sentido de volcar nuestras intervenciones e investigaciones a lo que ocurre en la cotidianidad y la convivencialidad. Un antecedente para ello es lo que nos viene señalando el Informe de las Naciones Unidas para el Desarrollo en Chile (2015), según el cual las personas no están respondiendo a la cuestión instrumental de la política (estrategias), sino a un deseo de colectividad que se ve imposibilitado en su despliegue por los procesos de despolitización e individualización.

Un Trabajo Social crítico puede generar otro conocimiento si en vez de responder a la instrumentalidad que atraviesan los indicadores y resultados esperados, genera una praxis del caminar-preguntando, en un acompañamiento de la producción de subjetividades. No se trataría entonces de acercarse a los fenómenos que investigamos en una entrada y salida al campo de estudio en tanto "objeto", sino a un interés por dar sentido de inteligibilidad a los discursos reivindicativos de la vida cotidiana. Esto quiere decir: 
poner en el debate público aquellas interpelaciones conflictivas que evidencian las áreas de injusticia social.

Se trata, en definitiva, de debatir públicamente la posibilidades de resistencia a los modos de relación social capitalistas que impregnan nuestras vidas con altos niveles de desgaste, productividad y endeudamiento y que, por lo mismo, pareciera, sumirnos en un acuerdo tácito y desesperanzado respecto de una transformación social.

Creemos que de la subjetividad de las vidas cotidianas emergen las preguntas más apremiantes por las condiciones de dignidad y, en este sentido, apostamos por un Trabajo Social crítico, capaz de asumir el destino de incertidumbre de la democracia que hoy vivimos: recuperando voces y formas de organización que nos permitan no solo producir conocimiento acerca de modos de relación social y sus áreas problemáticas, sino además interpelar la hegemonía de discursos orientados a la identidad de consumidores/as, para debatir fenómenos actuales; a saber, el trato social o lógicas criminalizantes y clasistas de control social, por ejemplo.

Desde esta perspectiva, proponemos como elementos constitutivos de una noción de politización de la vida cotidiana los procesos de legitimación y/o relación con los canales institucionales (si los hay), los procesos de autogestión, los momentos de manifestación y aparición en el espacio público, las tematizaciones políticas, el establecimiento (y argumentación) de las posiciones en conflicto y/o consenso, nuevas formas de participación y repertorios de manifestación, actuaciones de reforma o transformación de relaciones sociales, políticas y económicas en la praxis: capacidad de plantear proyectos o preocupaciones de futuro, exposición de demandas de carácter material y/o inmaterial.

Finalmente, desde las líneas de pensamiento brevemente esbozadas, emerge el interés por acercarse a un ejercicio disciplinario capaz de informarse acerca de las potencialidades y nuevos léxicos de lo colectivo, ámbito en el que se expresan malestares subjetivos pero también nuevos sentidos de la experiencia política y de la reunión pública. 


\section{Bibliografía}

Arendt, H. (1967). Sobre la revolución. (Trad. Pedro Bravo). Madrid: Revista de Occidente, S.A.

Arendt, H. (1973). Crisis de la República. (Trad. Guillermo Solana Alonso). Madrid: Taurus, S.A.

Arendt, H. (1958). The Human Condition. Chicago: University of Chicago Press. [Introduction by Margaret Canovan].

Arendt, H. (1984). La vida del espíritu. (Trad. de Ricardo Montoro y Fernando Vallespín). Madrid: Centro de Estudios Constitucionales.

Arendt, H. (2003). Conferencias sobre la filosofía política de Kant. (Trad. Carmen Corral). Barcelona: Paidós.

Beiner, R. (2003). Hannah Arendt y la facultad de juzgar. En Conferencias sobre la filosofía política de Kant (pp). Barcelona: Paidós.

Beck, U. (1998). La invención de lo político. (Trad. Irene Merzari). Buenos Aires: Fondo de cultura económica.

Beck, U. (2002). La sociedad del riesgo global. (Trad. Jesús Alborés Rey). Madrid: Siglo XXI, S.A.

Bondia, D. (dir.), Daza, F. y Sánchez, A. (coords.). (2015). Defender a quien defiende. Leyes mordaza y criminalización de la protesta en el Estado español. Barcelona: Icaria.

Deleuze, G. (2005). Lógica del sentido. (Trad. Miguel Morey y Víctor Molina). Barcelona: Paidós.

Deleuze, G. y Guattari, F. (1988). Mil mesetas. Capitalismo y esquizofrenia. (Trad. José Vásquez Pérez). Valencia: Pre-textos.

Foucault, M. (1992). Microfísica del poder. (Trad. Julia Varela, Fernando Alvarez-Uría). Madrid: La Piqueta.

Lechner, N. (1976). En la búsqueda de un concepto teóricamente perdido: la crisis. En: N. Lechner y J.J. Brunner, Dos notas sobre integración social. Santiago: FLACSO.

Lechner, N. (ed.). (1981). Estado y política en América Latina. México: Siglo XXI.

Lechner, N. (1986). Los miedos como problema político. (Ponencia leída en el seminario sobre "Culturas Urbanas", Barcelona, 1985). Santiago: FLACSO.

Nietzsche, F. (1973). Así habló Zaratustra. (Trad. EDAF). Barcelona: Círculo de Lectores S.A.

Panikkar, R. (2009). La puerta estrecha del conocimiento. (Trad. Germán Ancochea). Barcelona: Herder. 
Sánchez, C. (2003). Hannah Arendt, el espacio de la política. Madrid: Centro de Estudios Políticos y Constitucionales.

Yáñez Pereira, V. (2007). Visibilidad/Invisibilidad del Trabajo Social. Los fundamentos de una cosmología disciplinaria. Buenos Aires: Espacio.

\section{Recursos electrónicos}

Informe del Programa de las Naciones Unidas para el Desarrollo. PNUD-Chile. (2015), Los tiempos de la politización. Recuperado de http://www.cl.undp.org/content/chile/es/home/library/human_development/los-tiempos-de-la-politizacion.html

Consultado el 3, marzo, 2017

Informe RADDE (Red de Abogados por la Defensa de los Derechos Estudiantiles). Criminalización de la movilización estudiantil en Chile en el año 2011. Recuperado el 6 de mayo de 2016 de http://educacionparatodos.cl/wp-content/ uploads/2015/10/Informe-RADDE-2013.pdf Negri, A. (2016), Con el 15M se ha producido en España una ruptura antifascista. Recuperado el 6 de mayo de 2016 de https://www.diagonalperiodico.net/blogs/funda/entrevista-antonio-negri-con-15m-se-ha-producido-espana-ruptura-antifascista.html Tassin, E. (2010), La manifestación política más allá del acierto y el fracaso. Cali: Papers del Congreso colombiano de filosofía.

Recuperado el 5 de enero de 2016 de http://www.ub.edu/cdona/no$\mathrm{de} / 1005$ 